\section{REPROGRAMMING REGULATORY T CELLS (TREG) USING A MALT1 INHIBITOR FOR CANCER THERAPY}

${ }^{1}$ Peter Keller*, ${ }^{1}$ Irina Mazo, ${ }^{1}$ Yun Gao, ${ }^{1}$ Vijayapal Reddy, ${ }^{1}$ Francisco Caballero, ${ }^{1}$ Sam Kazer, ${ }^{2}$ Amina Fu, ${ }^{2}$ Yi Sun, ${ }^{3}$ Dannah Miller, ${ }^{3}$ Roberto Gianani, ${ }^{4} J a m e s ~ M a v i n,{ }^{5}$ Bret Stephens, ${ }^{6}$ Gregory Beatty, ${ }^{2}$ Russell Jenkins, ${ }^{2}$ Ulrich Von Andrian, ${ }^{7}$ Daniel Krappmann, ${ }^{2}$ Thorsten Mempel. ${ }^{1}$ Monopteros Therapeutics, Boston, MA, USA; ${ }^{2}$ Harvard Medical School, Boston, MA, USA; ${ }^{3}$ Flagship Biosciences, Broomfield, CO, USA; ${ }^{4}$ University of Utah, Salt Lake City, UT, USA; ${ }^{5}$ Rincon Biosciences, Salt Lake City, UT, USA; ${ }^{6}$ University of Pennsylvania, Philadelphia, PA, USA; ${ }^{7}$ Helmholtz Zentrum, Munich, Germany

Background MALT1 protease is a promising target in aggressive lymphomas ${ }^{1}$, and two phase 1 clinical trials in hematological cancers are ongoing (NCT03900598, NCT04876092). More recently, MALT1 protease inhibition was also shown to reprogram regulatory $\mathrm{T}$ cells (Treg) in solid tumors, causing them to lose their immunosuppressive function and secrete interferon-gamma (IFN). ${ }^{2}$ Changes in Treg metabolism in the tumor microenvironment (TME) may account for their destabilization and selective susceptibility to reprogramming in tumor tissue. ${ }^{3} 45$ While strong MALT1 inhibition can cause Treg depletion in blood and induce autoimmune toxicity, ${ }^{6}$ a therapeutic window for a differentiated MALT1 inhibitor that reprograms destabilized Treg in the TME before affecting Treg in healthy tissue may exist. ${ }^{2}$ MPT-0118 is an orally dosed MALT1 inhibitor developed to reprogram destabilized Treg in the TME without causing autoimmune symptoms. A Phase 1/ $1 \mathrm{~b}$ dose-escalation and cohort-expansion clinical trial evaluating MPT-0118 is underway (NCT04859777).

Methods Human xenograft models of lymphoma were used to assess the direct activity of MPT-0118 on MALT1-dependent (but not not MALT1-independent) hematologic tumors. Effects of MPT-0118 on solid tumors were determined in syngeneic cancer models. Human and mouse tumor tissues were evaluated for Treg reprogramming by in situ hybridization or flow cytometry. Patient-derived organotypic tumor spheroids were assessed for immune-mediated cell killing. Studies in rodents and dogs assessed pharmacokinetics (PK) and safety.

Results MPT-0118 was selective and effective in preventing growth of aggressive MALT1 protease-dependent lymphomas. Beyond direct activity on hematologic malignancies, MPT-0118 also increased anti-tumor immune responses as single-agent or in combination with anti-PD-1 in syngeneic tumor models that are otherwise unresponsive to immune checkpoint blockade (ICB). MPT-0118-treated syngeneic tumors showed an increase in IFN-secreting Treg, associated with decelerated tumor growth. PK studies reveal that MPT-0118 has a high volume of distribution, and effective inhibitor concentrations are reached in the murine tumors upon oral dosing. The drug candidate caused tumor-associated Treg to produce IFN without changing the frequency of Treg circulating in the blood. Ex vivo, MPT-0118 induced Treg reprogramming in tumors resected from patients with colorectal and endometrial cancers and cell killing in spheroids derived from patients with colorectal cancer.

Conclusions The MALT1 inhibitor MPT-0118 is a clinical candidate for treating MALT1-expressing lymphomas and Treginfiltrated solid tumors. MPT-0118 exploits the therapeutic opportunity presented by destabilized Treg in the TME. Treg reprogramming represents a novel strategy with the potential to improve responses to ICB therapy in a broad range of solid tumors.

\section{REFERENCES}

1. Nagel $D$, Spranger $S$, Vincendeau $M$, Grau $M$, Raffegerst $S$, Kloo $B$, Hlahla $D$, Neuenschwander M, Peter von Kries J, Hadian K, Dörken B, Lenz P, Lenz G, Schendel DJ, Krappmann D. Pharmacologic inhibition of MALT1 protease by phenothiazines as a therapeutic approach for the treatment of aggressive $A B C$ DLBCL. Cancer Cell 2012 December 11;22(6):825-37.

2. Di Pilato $M$, Kim EY, Cadilha BL, Prüßmann JN, Nasrallah MN, Seruggia $D$, Usmani SM, Misale S, Zappulli V, Carrizosa E, Mani V, Ligorio M, Warner RD, Medoff BD, Marangoni F, Villani AC, Mempel TR. Targeting the CBM complex causes Treg cells to prime tumours for immune checkpoint therapy. Nature 2019 June;570(7759):112-116.

3. Lim SA, Wei J, Nguyen TM, Shi H, Su W, Palacios G, Dhungana Y, Chapman NM, Long L, Saravia J, Vogel P, Chi H. Lipid signalling enforces functional specialization of Treg cells in tumours. Nature 2021 March;591(7849):306-311.

4. Zappasodi R, Serganova I, Cohen IJ, Maeda M, Shindo M, Senbabaoglu Y, Watson MJ, Leftin A, Maniyar R, Verma S, Lubin M, Ko M, Mane MM, Zhong H, Liu C, Ghosh A, Abu-Akeel M, Ackerstaff E, Koutcher JA, Ho PC, Delgoffe GM, Blasberg R, Wolchok JD, Merghoub T. CTLA-4 blockade drives loss of Treg stability in glycolysis-low tumours. Nature $2021 \mathrm{March} ; 591$ (7851):652-658.

5. Overacre-Delgoffe $A E$, Chikina M, Dadey RE, Yano $H$, Brunazzi EA, Shayan $G$, Horne W, Moskovitz JM, Kolls JK, Sander C, Shuai Y, Normolle DP, Kirkwood JM, Ferris RL, Delgoffe GM, Bruno TC, Workman CJ, Vignali DAA. Interferon- $\gamma$ drives Treg fragility to promote anti-tumor immunity. Cell 2017 June 1;169(6):11301141.e11.

6. Martin K, Junker U, Tritto E, Sutter E, Rubic-Schneider T, Morgan $H$, Niwa S, Li J Schlapbach A, Walker D, Bigaud M, Beerli C, Littlewood-Evans A, Rudolph B, Laisney M, Ledieu D, Beltz K, Quancard J, Bornancin F, Zamurovic Ribrioux N, Calzascia T. Pharmacological inhibition of MALT1 protease leads to a progressive IPEX-Like pathology. Front Immunol 2020 April 30;11:745.

http://dx.doi.org/10.1136/jitc-2021-SITC2021.861 